\title{
Investigating audiences' attitudes towards local radio programs: A case study of city of Esfahan
}

\author{
Faezeh Taghipour $^{\mathrm{a}^{*}}$, Mohammad Reza Iravani ${ }^{\mathrm{b}}$, Seyed Hamid Reza Hodaee ${ }^{\mathrm{c}}$ and Allahyar \\ Arabmomeni $^{\mathrm{d}}$
}

\author{
${ }^{a}$ Assistant Professor , Islamic Azad University, Khoraseghan Branch, Esfahan, Iran \\ ${ }^{b}$ Assistant Professor, Department of Social Work, Islamic Azad University of Khomeinishahr, Khomeinishahr Branch, Daneshjou Blvd, Iran \\ ${ }^{c}$ Master of Cultural Planning, Iran \\ ${ }^{d}$ Islamic Azad University of Khomeinishahr, Department of Human Science, Khomeinishahr Branch, Daneshjou Blvd, Iran

\section{CHR O N I C L E A B S T A C T}

Article history:

Received October 3, 2012

Received in revised format

30 November 2012

Accepted 30 November 2012

Available online

December 22012

Keywords:

Multimedia programs

Audience

Attitude

\begin{abstract}
For almost a century, radio stations have been some primary sources for presenting arts, entertainment, news, etc. and the primary concern on many studies is to understand audience attitude on this media. This paper attempts to investigate audience attitude on radio programs broadcasted in city of Esfahan, Iran. The proposed study selects random sample of 600 out of $1,745,428$ residence of this city where 345 people actively were listening to these programs, actively. All questions were designed in Likert scale and Cronbach alpha was 0.941, which was well above the desirable level and validated the survey. According our survey, the most popular part of radio programs was associated with news where $78.3 \%$ of the audiences were listening to these programs. According to our survey, audiences were mostly satisfied with family oriented programs and the mean score was 4.05. The other observation indicates that people have good attitude towards educational guidance programs (mean=3.37) and programs related to people and officials (mean=3.41). The results of Freedman test with Chi-Square value of 52.507 determines that there is meaningful difference among different components (mean difference $=-0.23$ and P-value $=0.022$ ). We have also performed an investigation to find out whether there is any difference between different components of this survey in terms of participants' personal characteristics such as age, gender, educational background and job. Our survey only confirms the mean difference in terms of job specifications and other personal characteristics did not have any impact on people's attitude. The other observation in our survey indicates that there is a difference between students and people with no job or housekeeper on their attitudes towards educational programs.
\end{abstract}

\section{Introduction}

For almost a century, radio stations have been some primary sources for presenting arts, entertainment, news, etc. and the primary concern on many studies is to understand audience attitude

* Corresponding author. Tel: + 989131064291

E-mail addresses: Faezeh.taghipour@gmail.com (F. Taghipour)

(C) 2013 Growing Science Ltd. All rights reserved.

doi: 10.5267/j.msl.2012.12.003 
on this media. There have been many programs to increase efficiency and effectiveness of media programs such as increasing training programs, reducing cost, etc. Dadgaran et al. (2013), for instance, studied important barriers on privatization of television (TV) media industry in Iran. They designed and distributed a questionnaire using a sample of 234 out of 600 graduate students who were enrolled in media communication studies and examined six hypotheses based on one-side tstudent. The survey investigated various factors influencing privatization of TV media industry. The results of the investigation indicated that the cost of TV production, people's interest on investing on TV media industry, short and long-term investment security, cultural obstacles, building appropriate culture and economical barriers impact media privatization, substantially.

Different media such as listening to radio or more specifically watching television for long time could create obesity as well. According to Boulos et al. (2012), obesity is a major public health concern in the United States. Over the past few decades, the increase in obesity among both adults and children has steadily grown at an alarming rate and is now reaching epidemic proportions. The increase in obesity has been associated with increases in a host of many deseases. Boulos et al. (2012) provided an interdisciplinary review of the direct and indirect techniques in which television impacts the obesity epidemic, and concluded with ways in which the negative influence of television on obesity could be reduced.

Matani et al. (2012) explained that Satellite channels are important tools for building a connection among people with the same nationality in various parts of the world. They presented a survey among 310 audiences of satellite channels and reported that that the demographic characteristics of the audiences including age, gender, and education could impact the level of gratification with the satellite channels. From the cognitive perspective, they considered the satellite channels as important tools for increasing their knowledge and from an emotional perspective; they considered these channels as enjoyable, entertaining and interesting. One of the ways to measure the effective of a media program is to learn more on people's attitude towards different programs. Sedrpoushan et al. (2012), for instance, reported that the consultation could change both welfare receivers' perception and their attitude, significantly.

Lee et al. (2010) investigated the nature of four different categories of mobile TV adopters - current, potential, continuous non-, and discontinuous user groups. They reported that the non-adoption rate of mobile TV of the continuous non-, and discontinuous user groups was higher than the adoption rate of the current and potential user groups. They also reported that less than half of the people who took part in this survey used TV on a mobile device were unwilling to use it again in the next twelve months, and more than half of them were not interested in using it within the coming year. They suggested that the discontinuous group seems to have been dissatisfied with the actual mobile TV compared with their evaluations and expectations. In their survey, all user groups were unwilling to pay any fee. No differences were also detected in the personality trait of innovativeness and mass media use behaviors among the four groups.

Lee et al. (2011), in other work, tried to investigate the factors impacting young people's mobile TV adoption behaviors ranging from non- and discontinuous to actual adoption. They reported that information required and newspaper's reading were negatively related to mobile TV adoption, while entertainment needs were detected to be a significant positive factor of the adoption likelihood. The results implied that young adults tended to adopt and implement mobile TV for entertainment purpose, rather than for informational purpose.

They also explained that perceived value predicted the adoption while perceived price as an available resource did not have an influence on the adoption. Inconsistent with the prior findings of people's mobile TV adoption and implementation as both positive information and entertainment sources, they reported that young adults were likely to adopt and implement mobile TV for entertainment and portability. When considering the capabilities of the technology, the results revealed young adults' 
perceptual and behavioral tendency toward the various implementation of the technology in the convergent media environment in which they were grown up.

Schuurman et al. (2009) in other study, compared the views from four different sources regarding context including possible mobile peak times, usage duration and usage goals and content for mobile TV. Williams et al. (2011) studied results from research associated with the implementation of television as a device, which supports social interaction between close-knit groups in settings that include more than two locations, each location being potentially equipped with more than one camera. They introduced the notion of a framing experience, as a specific scenario or situation within which social communication takes place. They also investigated on the effect the use of framing experiences, such as those described here, which could have on strategy and policy for service providers and regulators.

The proposed study of this paper investigates some audience attitude on radio programs broadcasted in city of Esfahan, Iran. The organization of this paper first presents details of our survey in section 2, section 3 presents the results of our findings and finally, concluding remarks are given in the last to summarize the contribution of the paper.

\section{The proposed study}

The proposed study selects random sample of 600 out of 1,745,428 residence of this city where 345 people actively were listening to these programs, actively. All questions were designed in Likert scale and Cronbach alpha (Cronbach, 1951) was 0.941, which was well above the desirable level and validated the survey. The proposed study of this paper considers the following four questions,

1. How is people's attitude towards educational guidance programs broadcasted on radio programs?

2. How is people's attitude towards informative guidance programs broadcasted on radio programs?

3. How is people's attitude towards entertainment programs broadcasted on radio programs?

4. How is people's attitude towards broadcasted programs in radio on improving relationship between government and local residence?

\section{The results}

In this section, we present details of testing four hypotheses based on t-student.

\subsection{The first hypothesis: The effects of educational guidance programs}

The first hypothesis is associated with the effects of educational guidance programs broadcasted on local radio on people's attitude. Table 1 shows details of our $t$ test.

\section{Table 1}

The results of t-student test on the first hypothesis

\begin{tabular}{|c|c|c|c|c|c|c|}
\hline Component & Mean & Standard deviation & Deviation from mean & t-value & Degree of freedom & P-value \\
\hline $\begin{array}{l}\text { Educational guidance } \\
\text { programs }\end{array}$ & 3.59 & 0.53 & 0.031 & 19.249 & 295 & 0.001 \\
\hline
\end{tabular}

As we can observe from the results of Table 1, the mean score for education guidance programs is well above the average and t-student remains meaningful when the level of significance is one percent. Therefore, we can conclude that educational guidance programs influence people's attitude, significantly. 


\subsection{The second hypothesis: The effects of informative guidance programs}

The second hypothesis is associated with the effects of informative guidance programs broadcasted on local radio stations on people's attitude. Table 2 shows details of our $t$ test.

Table 2

The results of t-student test on the second hypothesis

\begin{tabular}{|c|c|c|c|c|c|c|}
\hline Component & Mean & Standard deviation & Deviation from mean & t-value & Degree of freedom & P-value \\
\hline $\begin{array}{l}\text { Informative guidance } \\
\text { programs }\end{array}$ & 3.41 & 0.55 & 0.032 & 19.959 & 296 & 0.001 \\
\hline
\end{tabular}

As we can observe from the results of Table 2, the mean score for informative guidance programs is well above the average and t-student remains meaningful when the level of significance is one percent. Therefore, we can conclude that informative guidance programs influence people's attitude, significantly.

\subsection{The third hypothesis: The effects of entertainment programs}

The third hypothesis is associated with the effects of entertainment programs broadcasted on local radio stations on people's attitude. Table 3 shows details of our $t$ test.

\section{Table 3}

The results of t-student test on the third hypothesis

\begin{tabular}{lcccccc}
\hline Component & Mean & Standard deviation & Deviation from mean & t-value & Degree of freedom & P-value \\
\hline $\begin{array}{l}\text { Entertainment } \\
\text { programs }\end{array}$ & 3.37 & 0.55 & 0.032 & 11.659 & 296 & 0.001 \\
\hline
\end{tabular}

As we can observe from the results of Table 2, the mean score for entertainment programs is well above the average and t-student remains meaningful when the level of significance is one percent. Therefore, we can conclude that entertainment programs influence people's attitude, significantly.

3.4. The fourth hypothesis: The effects of radio programs on relationship between government and people

The fourth hypothesis is associated with the effects of entertainment programs broadcasted on local radio stations on people's attitude towards having better relationship between government and people. Table 4 shows details of our $t$ test.

\section{Table 4}

The results of t-student test on the fourth hypothesis

\begin{tabular}{lcccccc}
\hline Component & Mean & Standard deviation & Deviation from mean & t-value & Degree of freedom & P-value \\
\hline $\begin{array}{l}\text { The effect of radio } \\
\text { programs for }\end{array}$ & 3.44 & 0.69 & 0.040 & 11.190 & 299 & 0.001 \\
$\begin{array}{l}\text { improving relationship } \\
\text { between government } \\
\text { and people }\end{array}$ & & & & & & \\
\hline
\end{tabular}

As we can observe from the results of Table 4, the mean score for entertainment programs is well above the average and t-student remains meaningful when the level of significance is one percent. Therefore, we can conclude that local radio station programs impact people's attitude towards having better relationship between people and government.

\subsection{Freedman test}

We have also performed Freedman test to measure the relative importance of each four components and the test yields valid results where Chi-Square was 52.507 with 286 degree of freedom. Therefore, informative guidance programs was the first priority with relative importance of 2.93 followed by the 
effect of radio programs for improving relationship between government and people with relative ranking of 2.49. In addition, educational guidance programs comes third in terms of ranking with relative weight of 2.33 and entertainment programs come last in terms of priority with relative weight of 2.25 .

We have also performed an investigation to find out whether there is any difference between different components of this survey in terms of participants' personal characteristics such as age, gender, educational background and job. Our survey only confirms the mean difference in terms of job specifications and other personal characteristics did not have any impact on people's attitude. The other observation in our survey indicates that there is a difference between students and people with no job or housekeeper on their attitudes towards educational programs.

\section{Conclusion}

In this survey, we have performed investigated audience attitude on radio programs broadcasted in city of Esfahan, Iran. The proposed study selected random sample of 600 out of 1,745,428 residence of this city where 345 people actively were listening to these programs, actively. All questions were designed in Likert scale and Cronbach alpha was 0.941, which was well above the desirable level and validated the survey. According our survey, the most popular part of radio programs was associated with news where $78.3 \%$ of the audiences were listening to these programs. According to our survey, audiences were mostly satisfied with family oriented programs and the mean score was 4.05 . The other observation indicated that people had good attitude towards educational guidance programs (mean=3.37) and programs related to people and officials (mean=3.41). The results of Freedman test with Chi-Square value of 52.507 determined that there was a meaningful difference among different components (mean difference $=-0.23$ and P-value $=0.022$ ). We have also performed an investigation to find out whether there was any difference between different components of this survey in terms of participants' personal characteristics such as age, gender, educational background and job. Our survey only confirmed that the mean difference in terms of job specifications and other personal characteristics did not have any impact on people's attitude. The other observation in our survey indicates that there is a difference between students and people with no job or housekeeper on their attitudes towards educational programs.

\section{Acknowledgment}

The authors would like to thank all people who participated in our survey and shares their thoughts.

\section{References}

Boulos, R., Vikre, E.K., Oppenheimer, S., Chang, H., \& Kanarek, R.B. (2012). ObesiTV: How television is influencing the obesity epidemic. Physiology \& Behavior, 107(1), 146-153.

Cronbach, L. J. (1951). Coefficient alpha and the internal structure of tests. Psychometrika, 16(3), 297-334.

Dadgaran, S.M., Farhangi, A.A., Najafbeigi, R. \& Jame, R. (2013). Investigating the barriers on media privatization. Management Science Letters, 3(1), 159-164.

Lee, H., Ryu, J., \& Kim, D. (2010). Profiling mobile TV adopters in college student populations of Korea. Technological Forecasting and Social Change, 77(3), 514-523.

Lee, H., Kim, D., Ryu, J., \& Lee, S. (2011). Acceptance and rejection of mobile TV among young adults: A case of college students in South Korea. Telematics and Informatics, 28(4), 239-250

Matani, M., Hasanzadeh, R., \& Farhangi, A.A. (2012). The application of modern media with an emphasis on satellite: media use and gratification approach. Management Science Letters, 2(4), 1209-1218.

Schuurman, D., De Marez, L., Veevaete, P., \& Evens, T. (2009). Content and context for mobile television: Integrating trial, expert and user findings. Telematics and Informatics, 26(3), 293-305 
Sedrpoushan, N., Iravani, M.R., \& Mansourzadeh, N.K. (2012). A social work study on measuring the effects of social cognitive consultation on welfare receivers' entrepreneurship attitudes and behavior. Management Science Letters, 2(4), 1441-1446.

Williams, D., Ursu, M.F., Meenowa, J., Cesar, P., Kegel, I., \& Bergström, K. (2011). Video mediated social interaction between groups: System requirements and technology challenges. Telematics and Informatics, 28(4), 251-270. 